\title{
European Headache Federation guideline on idiopathic intracranial hypertension
}

\author{
Jan Hoffmann ${ }^{1^{*}}$ (D), Susan P Mollan ${ }^{2}$, Koen Paemeleire ${ }^{3}$, Christian Lampl ${ }^{4}$, Rigmor H Jensen ${ }^{5}$ \\ and Alexandra J Sinclair ${ }^{6}$
}

\begin{abstract}
Background: Idiopathic Intracranial Hypertension (IIH) is characterized by an elevation of intracranial pressure (ICP no identifiable cause. The aetiology remains largely unknown, however observations made in a number of recent clinical studies are increasing the understanding of the disease and now provide the basis for evidence-based treatment strategies.

Methods: The Embase, CDSR, CENTRAL, DARE and MEDLINE databases were searched up to 1st June 2018. We analyzed randomized controlled trials and systematic reviews that investigate $\mathrm{IH}$.

Results: Diagnostic uncertainty, headache morbidity and visual loss are among the highest concerns of clinicians and patients in this disease area. Research in this field is infrequent due to the rarity of the disease and the lack of understanding of the underlying pathology.

Conclusions: This European Headache Federation consensus paper provides evidence-based recommendations and practical advice on the investigation and management of $\mathrm{IH}$.
\end{abstract}

\section{Objective}

Idiopathic Intracranial Hypertension (IIH) is characterized by an elevation of intracranial pressure (ICP) with no identifiable cause [1]. Despite the fact that its aetiology remains largely unknown, the observations made in a significant number of recent clinical studies and the resulting increase in the understanding of its clinical picture have led to modifications in its diagnostic classification and provide the basis for evidence-based treatment strategies. This consensus paper is based on the current literature on diagnosis and treatment of $\mathrm{IIH}$ and provides evidence-based recommendations on its treatment where randomized-controlled trials are available.

\section{Background}

The entire clinical syndrome of IIH is defined in the diagnostic criteria established by Friedman et al. [2] (Fig. 1) whereas the associated headache is defined in the Headache Classification of the International

\footnotetext{
* Correspondence: jan.hoffmann@kcl.ac.uk

${ }^{1}$ Basic and Clinical Neuroscience, Institute of Psychiatry, Psychology and Neuroscience, Wellcome Foundation Building, Denmark Hill Campus, King's College London, London SE5 9PJ, UK

Full list of author information is available at the end of the article
}

Headache Society (IHS) [3] (Table 1). The term 'pseudotumor cerebri', in the past commonly used as a synonym for $\mathrm{IIH}$, is now used as an umbrella term that describes the chronic elevation of ICP regardless of its aetiology and further subdivides in the primary (IIH) and secondary forms [2]. The remit of this manuscript will exclusively focus on the diagnostic and therapeutic algorithm of primary IIH.

IIH is a disorder that mainly affects obese women of childbearing age. Its prevalence has been estimated between $0.5-2$ per 100,000 of the general population [4]. However, due to the lack of awareness of the clinical syndrome as well as its potential similarity to primary headaches including migraine, it has been suggested that the disorder may be underdiagnosed [5]. In contrast, given the strong association between obesity and elevated ICP, it can be expected that the increasing obesity in the general population will increase the prevalence as well as the socioeconomic burden of the disease $[1,6]$. This outlook underlines the importance of clear diagnostic criteria that allow an accurate diagnostic algorithm as well as recommending effective management strategies.

(c) The Author(s). 2018 Open Access This article is distributed under the terms of the Creative Commons Attribution 4.0 International License (http://creativecommons.org/licenses/by/4.0/), which permits unrestricted use, distribution, and reproduction in any medium, provided you give appropriate credit to the original author(s) and the source, provide a link to the Creative Commons license, and indicate if changes were made. 


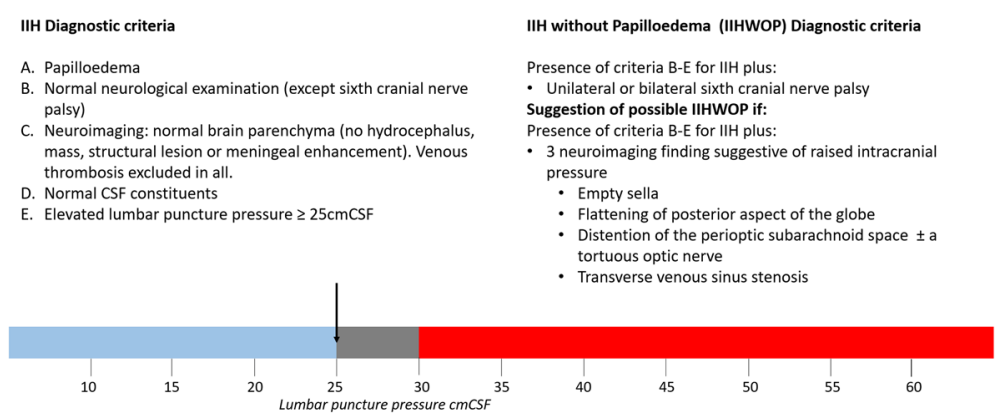

Fig. 1 Diagnostic criteria for $\| \mathrm{H}$ (Friedman criteria). Diagnostic criteria for $I \mathrm{H}$ and $I \mathrm{H}$ without papilloedema. Infogram demonstrating the "grey zone" in which LP pressure is normal in some individuals but can indicate pathologically raised ICP in some. Measurements in the grey zone need to be interpreted with caution and patients must fit the other criteria for $\mathrm{IH}$ for a diagnosis to be confirmed

\section{Clinical symptoms and diagnostic algorithm Clinical picture Headache}

Headache, present in up to $90 \%$ of $\mathrm{IIH}$ patients, is commonly the primary symptom leading IIH patients to seek medical advice [7, 8]. Headache is also the key factor driving reduced quality of life in IIH [9]. The features of IIH-related headache vary substantially and in the context of a limited amount of clinical studies that aim at characterizing them, the IHS-criteria remain relatively unspecific in their description. Patients commonly describe their headache as pressing, explosive with a frontal, retroorbital localization $[3,10]$. Frequently the headache has a migraine phenotype and overuse of analgesic is observed in over a third of IIH patients [11]. Phenotypic similarities may hamper its distinction from migraine and other headaches [7, 8, 12-17]. In order to establish the diagnosis of $\mathrm{IIH}$ it is required that the causality between the clinical symptoms and elevated ICP is demonstrated by a temporal relationship between headache onset and the identification of elevated ICP or an alleviation after a reduction of ICP. However, one study reported that over $20 \%$ of patients with other headache disorders also improve after lumbar puncture (LP) [18]. The second edition of the International Headache Classification (ICHD-2) detailed headache alleviation after

Table 1 Diagnostic criteria for $\mathrm{IH}$-related headache according to the International Classification of Headache Disorders (ICHD-3)

A. New headache, or a significant worsening of a pre-existing headache, fulfilling criterion $C$

B. Both of the following:

1. idiopathic intracranial hypertension $(\mathrm{IIH})$ has been diagnosed

2. cerebrospinal fluid (CSF) pressure exceeds $250 \mathrm{~mm}$ CSF (or $280 \mathrm{~mm}$

CSF in obese children)

C. Either or both of the following:

1. headache has developed or significantly worsened in temporal

relation to the $\mathrm{IH}$, or led to its discovery

2. headache is accompanied by either or both of the following:

a) pulsatile tinnitus

b) papilloedema

D. Not better accounted for by another ICHD-3 diagnosis pressure reduction was a required diagnostic criterion of $\mathrm{IIH}$, however in the recent ICHD-3 criteria this criterion has been removed as headache duration can vary substantially with almost two thirds of IIH-patients complaining of persisting chronic headache despite a normalization of ICP $[3,10,18,19]$. However, the precise onset of increased ICP and the related headache are difficult to establish, so the preliminary version of the present diagnostic ICHD-3 criteria (ICHD-3 beta) for IIH-headache have been field tested in a recent study and more sensitive and specific criteria have been suggested [18].

\section{Ophthalmic features}

Bilateral disc swelling, termed papilloedema when it is caused by raised ICP, is a cardinal feature of IIH and on examination it can be asymmetrical in $4 \%$ of cases [7, 20$25]$. Examination of the eye can be challenging and in case of diagnostic uncertainty, papilloedema should be confirmed by an experienced ophthalmologist. Exclusion of pseudopapilloedema is recommended to prevent unnecessary investigations and procedures. These include measurements of intraocular pressure, ruling out hypotony, and critical examination of the optic nerve as small hypermetropic discs, titled myopic discs, vitreous traction and disc drusen can all be mistaken for papilloedema. There is a high frequency $(40 \%)$ of diagnostic errors in IIH, with the main cause being an incorrect ophthalmic examination [26].

Raised ICP can lead to a number of visual symptoms including transient visual obscurations, visual blurring and double vision. All IIH patients with active papilloedema need close ophthalmological monitoring to evaluate the visual function and assess the risk of visual loss as in some the visual disturbances are progressive and may lead to prolonged ischemia of the optic nerve head resulting in complete and irreversible sight loss secondary to optic atrophy. The tests of visual function are important as no correlation between headache frequency 


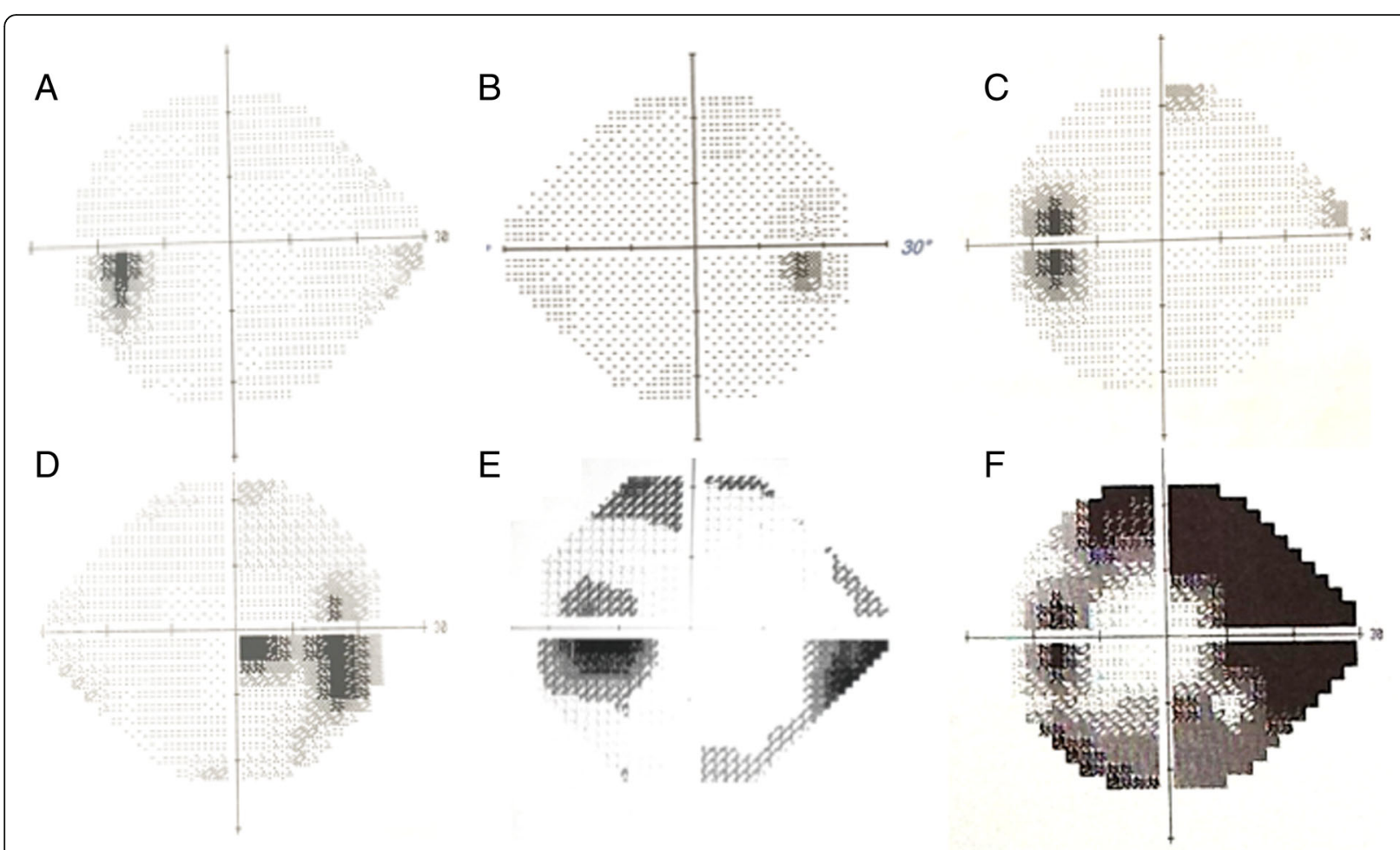

Fig. 2 Typical visual field defects in IIH. Common visual field defects seen in IIH with the Humphrey visual field analyser grey scale. a, Left eye with a slightly enlarged blind spot; $\mathbf{b}$, right eye with slightly enlarged blind spot; $\mathbf{c}$, Left eye obvious enlarged blind spot; $\mathbf{d}$, right eye with enlarged blind spot and paracentral scotoma; $\mathbf{e}$, left eye with enlarged blind spot and prominent inferior nasal step; $\mathbf{f}$, Left eye with enlarged blind spot, dense superior and inferior arcuate scotomas

and the degree of papilloedema has been demonstrated [27]. Data from a recent randomized-controlled clinical trial with acetazolamide for the treatment of $\mathrm{IIH}$, the IIH Treatment Trial (IIHTT), revealed that higher-grade papilloedema and a significant loss in visual acuity at presentation are associated with a higher risk of progression to visual field loss despite adequate treatment [28].

Ophthalmic examination should include: visual acuity, a pupil examination, formal visual field assessment and dilated fundal examination to evaluate the papilloedema. The typical visual field findings are that of an enlargement of the blind spot, peripheral constriction and or an inferior nasal step or partial arcuate defect [22, 29] (Fig. 2). To interpret visual fields with confidence a basic understanding of the plots (Table 2), reliability indices (Table 3), and global parameters (Table 3) is required. Visual field testing is a psychophysical test and can be demanding to interpret in any disease including IIH. Besides physical obstacles, cognitive factors including subject attention, motivation, fatigue, and response bias can influence the obtained thresholds. Improvement in reliability has been shown to improve with clear instructions [30]. Despite clear instructions in the IIHTT, performance failures were observed at some point in one fifth of the participants and were likely due to behavioural factors as the fields returned to baseline values on re-testing: therefore not deemed to be disease progression. Retesting is recommended where there is perimetric worsening, in the presence of unreliable indices (Table 3) [31].

The role of imaging the optic nerve head is becoming increasingly important. Qualitative analysis of photographic images remains useful for clinical records. Newer techniques such as wide field imaging using the $\mathrm{Optos}^{\mathrm{mi}}$ allow high resolution image capture through an undilated pupil, with a magnification tool to examine the optic nerve head (Fig. 3). Optical Coherence Tomography (OCT), in particular spectral domain OCT, offers a non-invasive technique for both qualitative and objective quantification of papilloedema that can support the detection of papilloedema [32-34]. OCT is found to be a valuable tool for quantification of papilloedema in longitudinal assessment: Fig. 4 demonstrates the clear improvement in papilloedema in a newly diagnosed IIH patient who undertook a low calorie diet for 6 weeks [35]. However, OCT has limitations. In cases of severe papilloedema errors occur in the automated software analysis which can lead to unreliable values, these scans need manual adjustment to ensure reliable results [36]. However as peripapillary retinal nerve fibre layer (RNFL) 
Table 2 Interpretation of Humphrey visual field plots. In static perimetry the stimulus is stationary but it changes its intensity until the sensitivity of the eye at the particular point is found. It is measured at preselected locations in the visual field. Most IIH patients have a threshold test where steps of $4 \mathrm{~dB}$ are used until detected then re-tested at every point in $2 \mathrm{~dB}$ steps

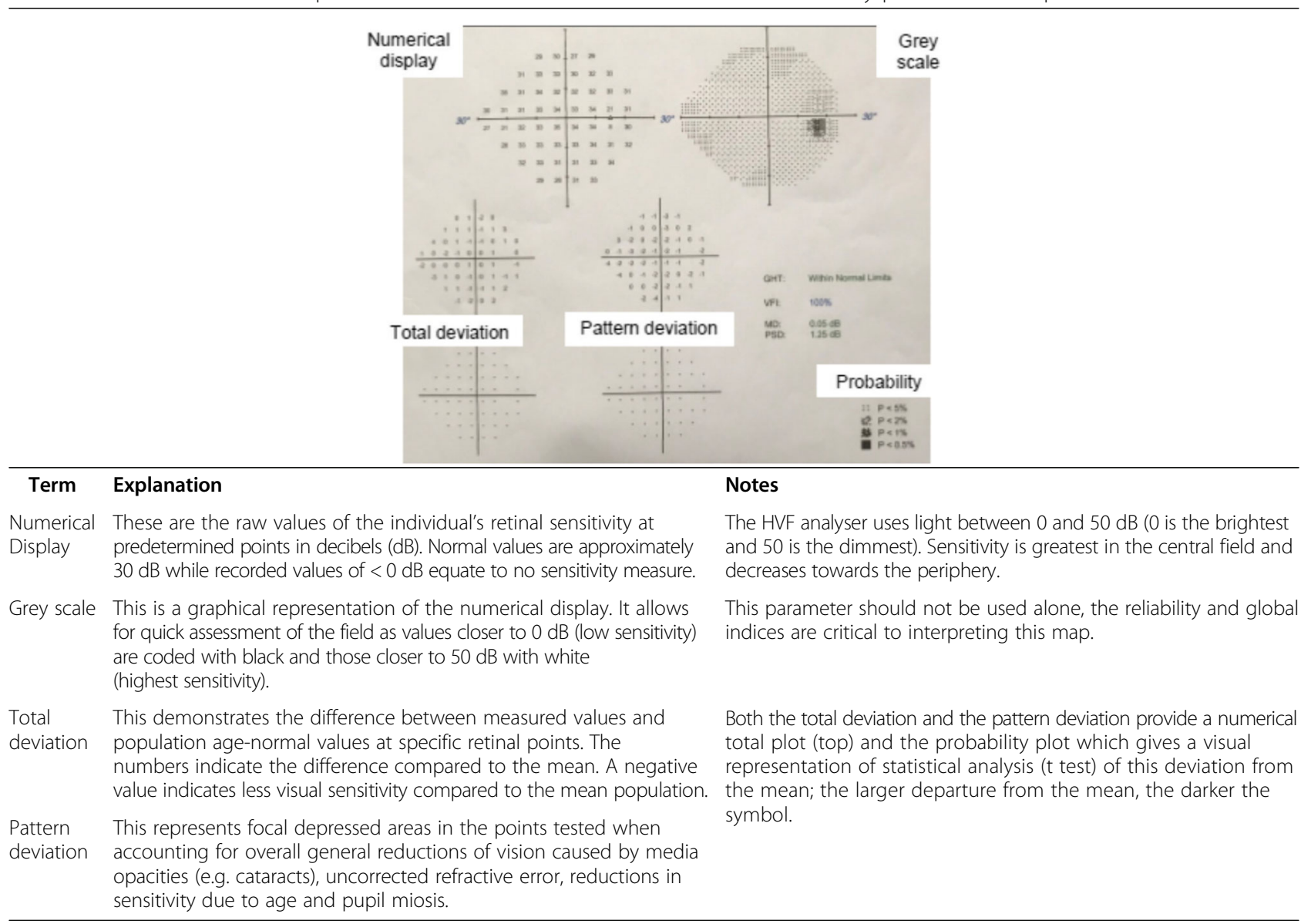

thickness resolves, most systems do not allow the distinction between reduction in oedema and optic atrophy as both conditions lead to a reduction in RNFL thickness [37]. Software enhancements on certain OCT platforms allow the determination of ganglion cell layer thickness and this may prove to be beneficial to correlate with visual loss. Some OCT platforms have the ability to capture short video footage which is useful to document location and presence of spontaneous venous pulsations (Additional file 1). OCT imaging supports the diagnosis and monitoring of papilloedema as demonstrated in Fig. 5 where there is an increase in the volume at the optic nerve head with recurrence of symptoms of headache and pulsatile tinnitus for one month in a patient previously in ocular remission, but does not mitigate the continued monitoring of all measures of visual function through clinical examination and formal perimetry.

\section{Other symptoms}

IIH can cause other symptoms, as well as headache and visual disturbances. Recent data however suggests that other systems may also be affected in $\mathrm{IIH}$, presumably as the result of increased ICP, although the exact mechanisms leading to these alterations remain largely unknown. In this context, structural changes in the olfactory nerve [38], which are associated with an olfactory dysfunction in up to $80 \%$ of IIH patients, have been demonstrated $[39,40]$. Nevertheless, despite an easy determination of olfactory function by the use of extended Sniffin' Sticks, this observation is not useful for the diagnosis or follow-up examinations in IIH as the effects of a variation in ICP may reflect on olfactory function with a significant delay.

A uni- or bilateral pulsatile tinnitus is commonly observed in $\mathrm{IIH}[7,8,41]$. Its underlying cause is not entirely elucidated but it is hypothesized that stenoses in the transverse sinus, which are commonly observed in IIH, may induce audible turbulences in blood flow. Nevertheless further studies are required to confirm this assumption.

Unilateral or bilateral sixth-nerve palsy may occur in $\mathrm{IIH}$ causing horizontal diplopia [42, 43]. The reason for this neurological deficit in the context of IIH has not been fully investigated. The pathophysiological mechanism has traditionally been thought to be due to compression against the 
Table 3 Interpretation of Humphrey visual field parameters

\begin{tabular}{|c|c|c|c|c|}
\hline Term & Explanation & Notes & \multicolumn{2}{|l|}{ Example } \\
\hline \multicolumn{5}{|c|}{ Reliability indices: } \\
\hline \multirow{2}{*}{$\begin{array}{l}\text { Fixation } \\
\text { Losses }\end{array}$} & \multirow{2}{*}{$\begin{array}{l}\text { Fixation is plotted, if the patient moves and } \\
\text { the machine re-tests and patient sees spot } \\
\text { then a fixation loss is recorded. }\end{array}$} & \multirow{2}{*}{$\begin{array}{l}\text { Fixation losses above } 20 \% \text { may significantly } \\
\text { compromise the reliability of the test. }\end{array}$} & \multicolumn{2}{|c|}{ Dos Single Field Analysis } \\
\hline & & & \multirow{2}{*}{$\begin{array}{l}\text { Fixation Monitor: } \\
\text { Fixation Target: } \\
\text { Fixation Losses: } \\
\text { False POS Errors: } \\
\text { False NEG Errors: } \\
\text { Test Duration: } \\
\text { Fovea: }\end{array}$} & \multirow{2}{*}{$\begin{array}{l}\text { Gaze/Blind Spot } \\
\text { Central } \\
4 / 21 \\
0 \% \\
9 \% \\
07: 35 \\
37 \mathrm{~dB}\end{array}$} \\
\hline $\begin{array}{l}\text { False POS } \\
\text { (Positive) } \\
\text { Errors }\end{array}$ & $\begin{array}{l}\text { Patient responds to the normal whirr noise of } \\
\text { the computer when it sounds as if is about to } \\
\text { present a light but does not. }\end{array}$ & $\begin{array}{l}\text { High false positive score occur in a } \\
\text { "trigger happy" patient. }<33 \% \text { is an } \\
\text { unacceptable test. }\end{array}$ & & \\
\hline $\begin{array}{l}\text { False NEG } \\
\text { (Negative) } \\
\text { Errors }\end{array}$ & $\begin{array}{l}\text { A brighter light is presented in an area in which } \\
\text { the threshold has already been determined and } \\
\text { the patient does not respond to it. }\end{array}$ & $\begin{array}{l}\text { High false negative score occurs in fatigued } \\
\text { or inattentive patients. }<33 \% \text { is } \\
\text { an unacceptable test. }\end{array}$ & \multicolumn{2}{|c|}{$\begin{array}{l}\text { OD- Right eye; } \\
\text { OS - Left eye. } \\
\text { Note the longer the test time the more } \\
\text { tired the patient will be. }\end{array}$} \\
\hline \multicolumn{5}{|c|}{ Global indices: } \\
\hline $\begin{array}{l}\text { Glaucoma } \\
\text { Hemifield } \\
\text { Test (GHT) }\end{array}$ & $\begin{array}{l}\text { This assesses clusters of points above and } \\
\text { below the horizontal meridian for any } \\
\text { significant difference. }\end{array}$ & $\begin{array}{l}\text { It describes the field as "Within normal } \\
\text { limits", "Borderline" or "Outside normal limits" }\end{array}$ & \multirow{3}{*}{\multicolumn{2}{|c|}{$\begin{array}{ll}\text { GHT: } & \text { Outside Normal Limits } \\
& \\
\text { VFI: } & 79 \% \\
\text { MD24-2: } & -8.85 \mathrm{~dB} P<0.5 \% \\
\text { PSD24-2: } & 9.79 \mathrm{~dB} P<0.5 \%\end{array}$}} \\
\hline VFI & & & & \\
\hline Mean & A measure of overall field loss & & & \\
\hline $\begin{array}{l}\text { deviation } \\
\text { (MD) }\end{array}$ & & & \multirow{2}{*}{\multicolumn{2}{|c|}{$\begin{array}{l}24-2 \text { denotes the test strategy } \\
\text { ( } 24 \text { degrees temporally and } 30 \text { degrees } \\
\text { nasally and tests } 54 \text { points). }\end{array}$}} \\
\hline $\begin{array}{l}\text { Pattern } \\
\text { standard } \\
\text { deviation } \\
\text { (PSD) }\end{array}$ & $\begin{array}{l}\text { Measure of focal loss or variability within the } \\
\text { field taking into account any generalised } \\
\text { depression. }\end{array}$ & $\begin{array}{l}\text { An increased PSD is more indicative of } \\
\text { glaucomatous field loss than MD. }\end{array}$ & & \\
\hline $\begin{array}{l}\text { Probability } \\
\text { values }\end{array}$ & $\begin{array}{l}\text { These indicate the significance of the defect } \\
<5 \%,<2 \%,<1 \% \text { and } 0.5 \% \text {. }\end{array}$ & $\begin{array}{l}\text { The lower the } p \text { value the greater its clinical } \\
\text { significance and the lesser the likelihood of } \\
\text { the defect occurring by chance. }\end{array}$ & \multicolumn{2}{|c|}{$\begin{array}{l}: P<5 \% \\
\therefore P<2 \% \\
P<1 \% \\
P<0.5 \%\end{array}$} \\
\hline
\end{tabular}

petrous ligament or the ridge of the petrous temporal bone, or stretching along the intracranial course of the nerve.

Cognitive function has been reported to be affected in $\mathrm{IIH}$. While a number of small uncontrolled studies, which occasionally focused only on single neuropsychological domains, suggested a relationship between IIH and cognitive decline [44-46], Yri et al. demonstrated in an extensive prospective case-control study that IIH is associated with a global cognitive dysfunction with the most extensive deficit in reaction time and processing speed [47]. Interestingly, the results of this study reveal that despite an improvement of ICP and headache after 3 months of adequate treatment, the cognitive dysfunction appears to persist raising the question if IIH-related cognitive decline is the result of more complex mechanisms rather than the direct effect of mechanical compression. These neuropsychological deficits may hamper significantly a professional reintegration after prolonged absence from work.

\section{Investigations}

\section{Neuroimaging}

Brain imaging is an essential part of the diagnostic algorithm and MRI should be considered the gold standard of care to exclude secondary causes of elevated ICP and to identify structural alterations associated with IIH. These include an empty sella turcica (or at least significant changes in size, shape and volume of the pituitary gland) and a flattening of the posterior optic globe. IIH also leads to an enlargement of the optic nerve sheath and an increased tortuosity of the optic nerve [12, 4851]. However, the volume of the optic nerve is not affected [12]. In contrast to early imaging studies based on plain film X-ray imaging that suggested a reduced ventricle size (slit-like ventricles) as indicative for IIH [52], data based on CT and MR imaging techniques demonstrates that size and volume of the lateral ventricles are not altered in IIH [49, 53].

Diagnostic brain imaging in IIH should always include a CT- or MR venography to exclude a venous sinus thrombosis as even clinically inapparent microthromboses may induce a venous outflow obstruction that increases ICP [54]. Furthermore the venography may demonstrate the presence of uni- or bilateral transverse sinus stenoses (TSS) as these are frequently observed in IIH patients with reported prevalence rates of up to $90 \%$ $[51,55,56]$. However, if TSS are cause or consequence of elevated ICP remains controversial. Additionally, 


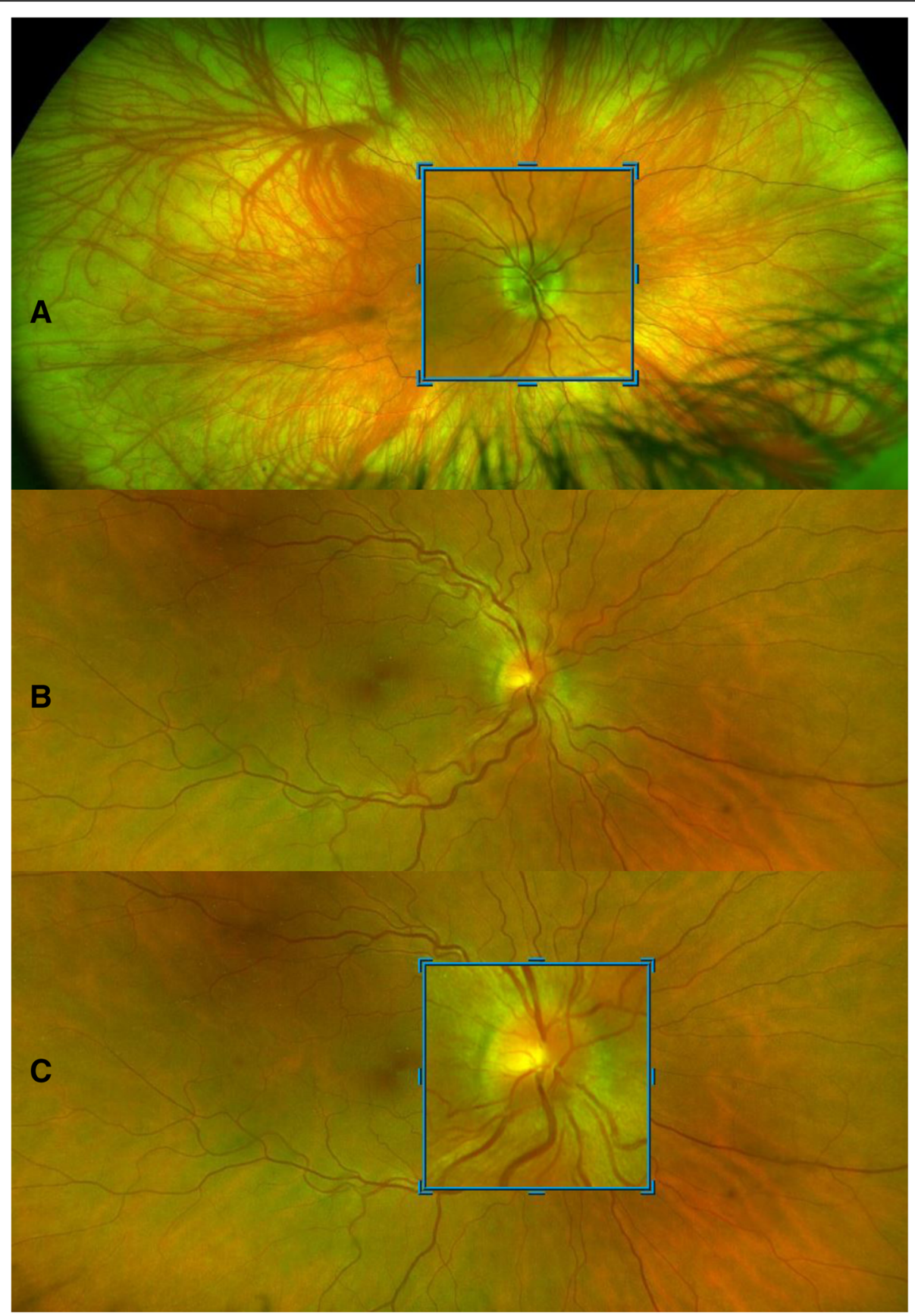

Fig. 3 Wide-field imaging using. Wide-field imaging with the Optos ${ }^{T M}$ through an undilated pupil in a, normal patient and $\mathbf{b}$, a patient with $I H$. a, normal fundus with blue high magnification box to inspect the optic nerve. Peripapillary atrophy $360^{\circ}$ around the disc which is normal. Note the lashes seen inferiorly as artefact on image. $\mathbf{b}$, right optic nerve which has grade 2 Frisen swelling where there is elevation of the optic disc margin $360^{\circ}$, loss of the clear optic disc margin as seen in $\mathbf{a}$. $\mathbf{c}$, the high magnification tool allows excellent visualisation of the swelling without degradation of the image

asymmetry of the transverse sinus can occur in $50 \%$ of healthy individuals [57].

Despite the value of neuroimaging in the diagnostic workup of $\mathrm{IIH}$, it does not replace the need for a measurement of lumbar opening pressure as imaging abnormalities show a large interindividual variation and none of the findings are pathognomonic of IIH hence imaging findings only serve as supportive evidence for the diagnosis of IIH.

\section{Lumbar puncture}

LP is mandatory in the diagnostic algorithm of IIH. In addition to a normal CSF composition, diagnostic criteria 

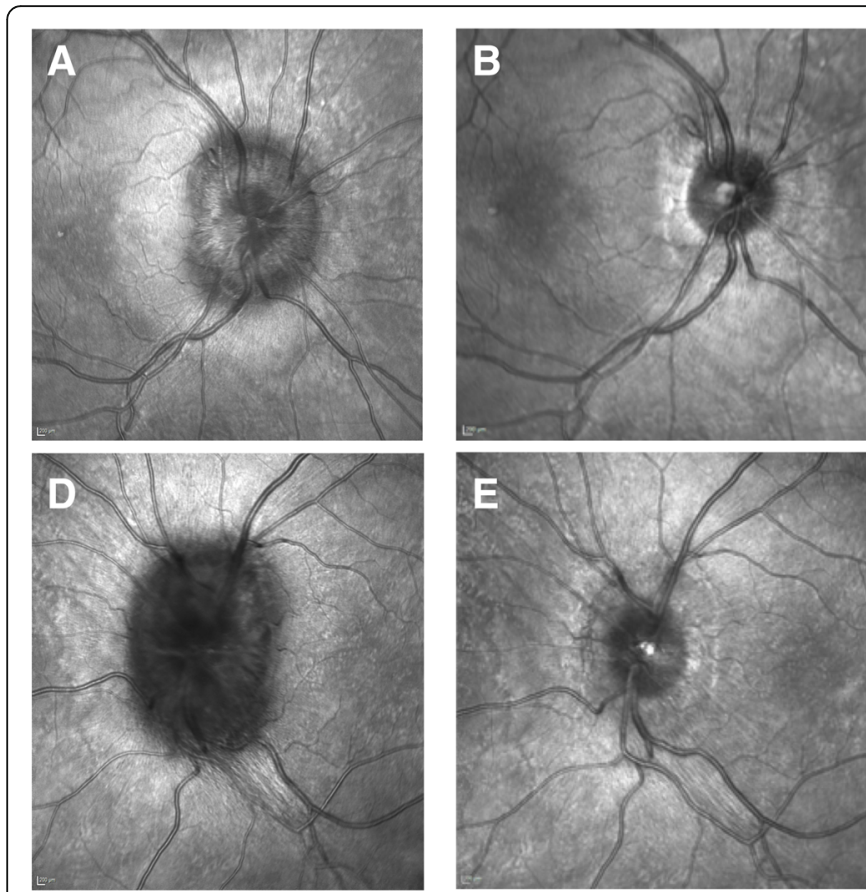
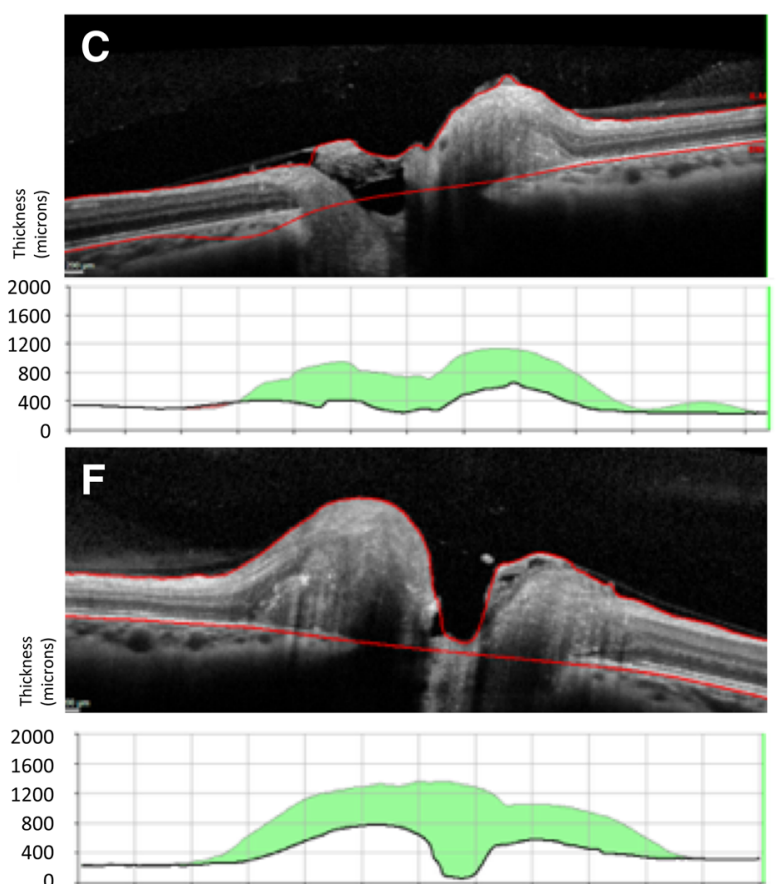

Fig. 4 Optical coherence tomography highlighting improvement of papilloedema. OCT is useful for monitoring of changes in papilloedema. a, Right eye infrared (IR) image of a swollen optic nerve. Note the Paton's lines (circumferential lines) between 9 o'clock and 11 o'clock. b, Right eye IR image the nerve following a low calorie diet 6 weeks later. Note the tidemark changes of the extent of the previous oedema. c, Right eye cross-sectional image half way through the optic nerve head. Note the high line indicates the height of the swelling at diagnosis and the green volume reduction from the first scan to the most recent one (in this case 6 weeks). $\mathbf{d}$, Left eye IR image of a swollen optic nerve. Note the difference between $\mathbf{a}$ and $\mathbf{d}$, indicating asymmetric papilloedema with worse papilloedema in the left eye. e, Left eye IR image the nerve following a low calorie diet 6 weeks later. Note the tidemark changes of the extent of the previous oedema. $\mathbf{f}$, Left eye cross-sectional image half way through the optic nerve head. Note the high line indicates the height of the swelling at diagnosis and the green volume reduction from the first scan to the most recent one (in this case 6 weeks)

require that opening pressure, which should be measured in the lateral decubitus position with stretched legs and without sedative medications, should not exceed 25 $\mathrm{cmH}_{2} \mathrm{O}$ in adults and $28 \mathrm{cmH}_{2} \mathrm{O}$ in children [2, 58, 59]. Increases of ICP may also occur intermittently, in particular in IIH patients without papilloedema $[60,61]$. Therefore, if IIH is suspected but opening pressure lies within the normal range during the initial assessment, a second measurement or even continuous monitoring could be considered [61-63]. Conversely, pressures above 25 $\mathrm{cmH}_{2} \mathrm{O}$ can occur in normality [64], with pressures in the range $25-30 \mathrm{cmH}_{2} \mathrm{O}$ constituting a grey area that could be pathological or normal and should be interpreted with caution [43]. Patients with pressures in this "grey zone" should be evaluated cautiously to ensure they meet the other aspects of the IIH diagnostic criteria [43].

\section{Blood tests}

Blood tests should be performed for the exclusion of secondary causes of elevated ICP or other medical conditions that may clinically present with similar symptoms. Blood test should be tailored to the individual patient's presentation. In the absence of typical phenotypic characteristics of IIH (obese female of childbearing age) blood tests to exclude secondary causes of pseudotumor cerebri are key. Excluding conditions that increase the likelihood of a sinus vein thrombosis, which could obstruct venous outflow, may be performed. These could include analysis of coagulation parameters to identify hypercoagulable states as well as a search for diseases that are associated with a higher risk of venous (micro-) thrombosis such as systemic lupus erythematosus and infections of the middle ear or mastoid. Endocrine disorders that may mimic IIH symptoms include Addison's disease, Cushing's syndrome, hypoparathyroidism as well as the use of growth hormones and may need to be excluded. Other medical conditions that may induce a secondary increase of ICP and should be identified via serologic examinations include systemic infections, uraemia, renal failure and anaemia [65] (Table 4).

\section{Treatment}

\section{Surgical treatment}

Surgical management is essential for IIH patients with rapidly declining visual function. The evidence base for choice 


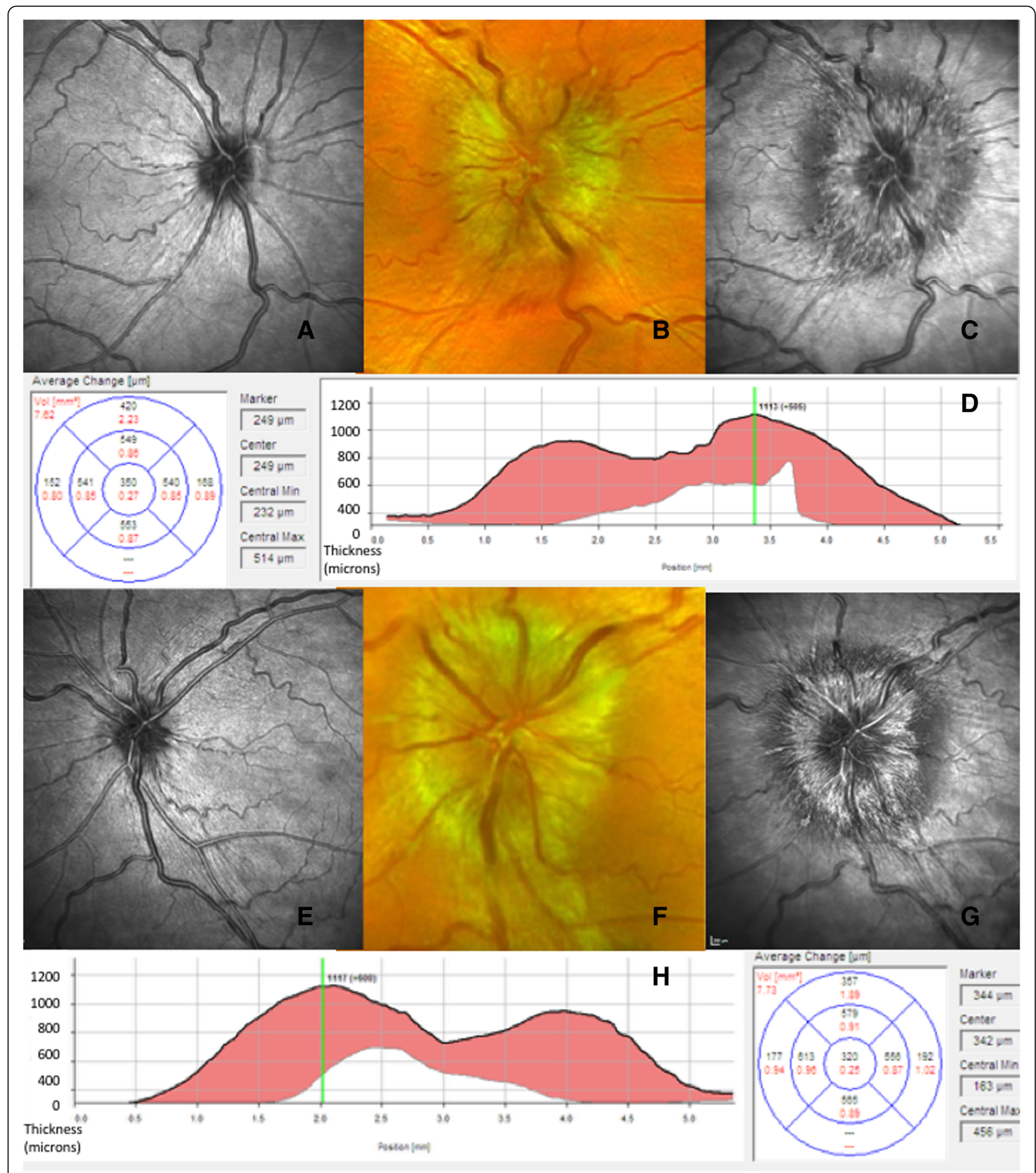

Fig. 5 (See legend on next page.) 
(See figure on previous page.)

Fig. 5 Optical coherence tomography highlighting worsening of papilloedema. OCT is useful for monitoring of changes in papilloedema. a, Right eye infrared (IR) image of a normal small optic nerve in a patient in $\mathrm{IH}$ with ocular remission. Note the tidemark changes of the extent of the previous oedema. $\mathbf{b}$, Colour photograph of right optic nerve with swelling and haemorrhage with recurrence of symptoms. $\mathbf{c}$, Right eye IR image taken at the same time as $\mathbf{b}$. Note the extent of the oedema and the optic nerve is more visible with the OCT image compared to the photo. $\mathbf{d}$, Right eye cross-sectional image half way through the optic nerve head. Note the high line indicates the height of the swelling at this visit and the red volume increase is from the last OCT scan to the most recent one. e, Left eye IR image of a normal small optic nerve in a patient in IIH with ocular remission. Note the tidemark changes of the extent of the previous oedema. $\mathbf{f}$, Colour photograph of left optic nerve with swelling and cotton wool spot changes with recurrence of symptoms. $\mathbf{g}$, Left eye IR image taken at the same time as $\mathbf{f}$. Note the extent of the oedema and the optic nerve is more visible with the OCT image compared to the photo. $\mathbf{h}$, Left eye cross-sectional image half way through the optic nerve head. Note the high line indicates the height of the swelling at this visit and the red volume increase is from the last OCT scan to the most recent one

of surgical technique is lacking and practice varies internationally and with surgeon preference. CSF diversion procedures including ventriculo-peritoneal, lumbo-peritoneal, and less frequently ventriculo-atrial shunting may be utilised. Ventriculo-peritoneal shunts are preferred due to lower revision rates compared to lumbo-peritoneal shunts (1.8 versus 4.3 revisions per patient respectively) [66]. Ventriculo-peritoneal shunts are typically placed using

Table 4 Medical conditions that may induce a secondary elevation of ICP or produce symptoms that may mimic IIH (adapted from

$[2,25,66-69])$

1. Medical disorders that may induce a sinus vein thrombosis or that may

cause a venous outflow obstruction through other mechanisms:

- Thrombophilia and other hypercoagulable conditions

- Systemic lupus erythematodes

- Infections of the middle ear or mastoid

- CNS- infections

- Increased right heart pressure with pulmonary hypertension

- Chronic obstructive pulmonary disease

- Superior vena cava syndrome

- Arteriovenous fistulas

- Glomus tumour

- Tumour process that may compress parts of the venous outflow system

2. Medications

- Fluoroquinolones [70]

- Tetracycline

- Vitamin A and retinoids

- Anabolic steroids

- Withdrawal of corticosteroids (in particular after prolonged administration)

- Administration of growth hormone

- Lithium

- Nalidixic acid

- Oral contraceptives

- Levonorgestrel implant system

- Amiodarone

- Cyclosporine

- Cytarabine

3. Other medical conditions

- HIV

- Syphilis

- Borreliosis

- Varicella

- Addison's disease

- Hypoparathyroidism

- Obstructive sleep apnoea

- Pickwickian syndrome

- Uraemia

- Severe iron deficiency anaemia

- Renal failure

- Turner syndrome

- Down syndrome neuro-navigation and adjustable valves (anti-gravity or anti-siphon devices) that can reduce the risk of low pressure headaches [66]. However, ventriculo-peritoneal shunt insertion leads to a temporary driving restriction in some countries such as the United Kingdom. Lumbo-peritoneal shunting may be considered but should be avoided in those with low lying cerebellar tonsils due to the risk of post-operative cerebellar tonsillar descent. Shunt revision is common with $51 \%$ requiring revision and multiple revisions required in 30\% [67]. Complications can occur including abdominal pain, shunt obstruction, migration and infection, low pressure headaches and subdural haematoma [67, 68]. An alternative to shunting is optic nerve sheath fenestration (ONSF) [69] which is more cost effective in some health care systems than CSF shunting [66]. But, this procedure also has a $26 \%$ revision rate, due to closing over of the fenestration, with an ensuring rise in ICP and consequent potential for further visual deterioration [66]. Headache improvement after ONSF is variable (one third to one-half have no headache response) [70].

The Neuro-Ophthalmology Research Disease Investigator Consortium (NORDIC) are currently planning a randomised controlled surgical trial, SIGHT, which will compare shunting with ONSF and acetazolamide. The trial will recruit patients with a severe visual loss defined as a parametric mean deviation between $-6 \mathrm{~dB}$ and $-27 \mathrm{~dB}$ assessed on the Humphrey visual field analyser.

\section{Endovascular stenting}

Venography brain imaging in IIH frequently demonstrates venous sinus stenosis $[55,71]$. These stenoses typically regress after CSF drainage which induces reduction of ICP, consequently the stenoses are thought to represent an effect of raised ICP not the underlying cause [72]. The extent of the stenoses does not correlate with ICP or predict the risk of visual loss [55]. Some centres are conducting venous sinus stenting to treat IIH but utility is debated. Case series have reported improvement in symptoms of intracranial hypertension, however case selection is not randomised which can lead to selection bias and there are a lack of long term outcomes [73]. Complications of the procedure are reported and include a short-lived ipsilateral headache in many, 
stent-adjacent stenosis that requires retreatment in a third, and in rare cases vessel perforation leading to acute subdural haematoma, stent migration, thrombosis and death [73]. The comparative efficacy of stenting and shunting is not established, nor are the long-term efficacy, revision rate and safety data. There may be a role in some highly selected IIH patients [74].

We do not advocate CSF diversion or shunting techniques to treat isolated headache symptoms due to the poor outcomes (ongoing headache in $68 \%$ at 6 months, $77 \%$ at 12 months and $79 \%$ at 2 years post-shunting), high revision rates and risk of complications [67]. There is insufficient evidence to support venous stenting to exclusively treat headache.

\section{Disease modification through weight loss}

There is a clear association between IIH and weight with over $90-95 \%$ of patients being obese [4]. Additionally, $\mathrm{IIH}$ is reported in the context of gaining $5-15 \%$ of body weight [75]. Weight loss is the only established disease modifying therapy in IIH [76]. Consequently, patients should be sensitively counselled about the importance of weight loss. However, the amount of weight loss required is not well established. Additionally, the optimal method of weight loss is uncertain. Dietary strategies are notoriously difficult to achieve and maintain in the long term $[77,78]$. The role of bariatric surgery is being increasingly suggested as a lasting therapy to induce IIH remission.

Bariatric surgery leads to greater weight loss compared to dietary regimes, with mean reduction in body mass index (BMI) of $7.05-15.34 \mathrm{~m} / \mathrm{kg}^{2}$ at 12 months [79] and significant sustained long term weight loss [80]. Bariatric surgery has been found to be cost effective for other obesity related conditions with very low associated mortality $(0.05 \%-0.14 \%$, which is akin to laparoscopic cholecystectomy) $[79,81,82]$. A systematic review of the IIH cases treated with bariatric surgery report $100 \%$ resolution of papilloedema and 90\% experience headache improvement [83]. A randomised control trial evaluating bariatric surgery in IIH is underway (IIH Weight Trial) [84].

\section{Symptomatic therapy with therapeutics Acetazolamide}

Therapeutic agents currently used in IIH aim to reduce ICP through reduction in CSF secretion. There are few therapeutic options and the recent Cochrane review reported: "the two included randomised controlled trials showed modest benefits for acetazolamide for some outcomes, there is insufficient evidence to recommend or reject the efficacy of this intervention, or any other treatments currently available, for treating people with $\mathrm{IIH}$ [85]". The IIHTT is the largest RCT to date and reports improvement in visual field function in patients with mild visual loss when treated with acetazolamide [86].
Benefits were most marked in those with the most marked papilloedema. However high doses of acetazolamide were used (greater than $40 \%$ of patients were treated with $4 \mathrm{~g}$ of acetazolamide daily) and this may not be tolerable. Previous studies have demonstrated that $48 \%$ of patients discontinue acetazolamide when doses of just $1500 \mathrm{mg}$ are utilised [87]. Side effects include paraesthesia, dysgeusia, vomiting and diarrhoea as well as malaise, fatigue and depression [88, 89]. Acetazolamide is the only therapeutic that has been evaluated in RCT and is regarded as the first line therapy for IIH. However, not all clinicians prescribe acetazolamide for IIH due to the limitations of the evidence base highlighted by the 2015 Cochrane review in conjunction with the potential side effect profile.

In pregnancy the use of acetazolamide is controversial. Data from case series $(n=50 \mathrm{IIH}$ patients using acetazolamide in the first trimester) has not identified an increased risk of foetal malformations although animal data has highlighted teratogenic effects $[90,91]$.

\section{Alternative therapeutics}

A number of alternative therapeutic agents are used in $\mathrm{IIH}$, however there is little evidence to support their use.

In animal studies, intravenous and intraventricular high dose furosemide has been shown to reduce CSF secretion by $20-50 \%$ [92-95]. However, clinically relevant routes of delivery and dosing have not been studied. A paediatric case series $(n=8)$ demonstrated that together acetazolamide and furosemide reduced ICP over 6 weeks, however the absence of a control group limits interpretation [96]. Bumetamide does not reduce CSF secretion in animal studies, and human studies have not been conducted [92].

Amiloride administered into the carotid artery in animal models reduces CSF secretion by up to $50 \%$ [97, 98]. But these studies have not used clinically relevant doses or routes of delivery.

Octreotide has been hypothesised to manipulate CSF secretion as there are somatostatin receptors on the choroid plexus [99]. A prospective open-label study of 26 patients reported resolution of papilloedema in 92\% of cases however cautious interpretation is needed in the absence of a control group [100].

Topiramate utility in IIH has been suggested by an open label study which randomly assigned 40 patients to acetazolamide or topiramate. They demonstrated treatment equivalence with all patients experiencing improvement in visual fields (ICP was not measured) [101]. Topiramate may have additional advantages in $\mathrm{IIH}$ as it can induce weight loss and has efficacy as a migraine preventive therapy [102-105]. Recently reported in vivo studies demonstrated that both subcutaneous and oral administration of topiramate significantly lowers ICP in rodents whilst other drugs tested, including 
acetazolamide, furosemide, amiloride and octreotide, did not significantly reduce ICP [106].

\section{Novel therapeutics}

Future therapies would ideally control ICP acutely as well as treat the underlying disease process through weight loss. There is growing interest in the role of gut neuro peptides in IIH. The gut peptide glucagon-like peptide-1 (GLP-1) regulates insulin secretion and weight, and currently GLP-1 mimetic drugs are used extensively to treat diabetes (without risk of hypoglycaemia) and obesity [107]. Recent in vitro assays have demonstrated that the GLP-1 receptor agonist exendin-4 reduces CSF secretion [108]. Additionally, clinically relevant doses of exendin-4 dramatically reduced ICP in rodents with raised ICP $(44 \%$ reduction in ICP within $10 \mathrm{~min}$ of dosing with effect maintained for $24 \mathrm{~h}$ [108]. A clinical trial is currently underway exploring the physiological effects of exenatide in reducing ICP in $\mathrm{IIH}$.

Therapeutic agents inhibiting the actions of 11Beta hydroxysteroid dehydrogenase type 1 (11 $\beta$-HSD1) have been proposed in IIH. 11 $\beta$-HSD1 is an enzyme which converts inactive cortisone to active cortisol and consequently regulates local cortisol availability, a key determinant of fluid secretion [109]. 11ß-HSD1 inhibitors have been shown to reduce intraocular pressure through reduction of aqueous humour production by the ocular ciliary body [110]. Akin to this mechanism, 11 $\beta-H S D 1$ is functionally active in the CSF secreting choroid plexus epithelial cells [111]. In patients with IIH, reduction in ICP correlates with reduction in global $11 \beta$-HSD1 activity measures [111]. 11 $\beta$-HSD1 inhibitors have been developed to treat obesity and metabolic syndrome. A phase 2 randomised controlled trial has been conducted in IIH which assesses a specific 11 $\beta$-HSD1 inhibitor (AZ4017), results are awaited [112].

\section{Managing headache}

Headache is the predominant morbidity in IIH and significantly reduces quality of life [9]. Headaches occur not only during the active stages of the disease when ICP is elevated, but frequently continue even after the ICP has settled [10, 67]. In those IIH patients with resolved papilloedema (IIH in ocular remission), the ongoing headaches cause significant morbidity. Evidence to guide headache management is very limited. Principles of managing headache in IIH could include [113]:

1. In those IIH patients with ongoing raised ICP, weight loss has been shown to significantly improve the Headache Impact Test 6 score (HIT-6) as well as headache severity, frequency and acute analgesic use [114]. Interestingly acetazolamide does not improve headache disability scores on the HIT-6 [86].
2. Medication-overuse headaches are a frequent co-morbidity in IIH (37\%) and patients will likely benefit from withdrawal [11].

3. Headache phenotype should be carefully evaluated to look for features of co-existing migraine. In those with IIH in ocular remission and migraine or in those with migraine-like headache with active IIH, acute and preventive strategies may be useful although there are no dedicated studies in this area. Preventive strategies may have particular benefit for those patients in whom the ICP is settling (IIH in ocular remission). Choice of migraine prevention should consider avoiding drugs that induce weight gain. Potential choices could include topiramate, candesartan and onabotulinum toxin $\mathrm{A}$, although there is no evidence of efficacy of these drugs in the setting of IIH $[113,115]$.

\section{Therapeutic lumbar puncture}

Therapeutic serial LPs are not advocated as a long-term treatment strategy for IIH. Although LP induces a transient reduction of CSF pressure the effect is typically short lived with pressures rising rapidly after the procedure [116]. Therapeutic LP has limited application for managing headache, as headache improves in $71 \%$, but the improvement is small ( 1 point on the verbal rating score $0-10)$ and there is also a $64 \%$ chance of a headache exacerbation in the week following LP in IIH patients [117]. Additionally, IIH patients frequently report a very negative and emotional experience when they undergo a LP $[118,119]$. In the short term, LP may have a role as a temporising procedure to preserve vision in patients with fulminant IIH awaiting an imminent CSF diversion procedure.

\section{Pregnancy}

Pregnancy can potentially limit the ability to perform neuroimaging studies for investigation and restrict therapeutic options. Hence the management of those who either present in pregnancy for the first time with IIH or for the majority who become pregnant during the course of their disease management should be determined on a case-by-case basis [120-122].

Patients should be cautioned about excessive weight gain during pregnancy that could precipitate a worsening of their IIH. If there is access to a weight management service, this is useful so that clear advice regarding weight gain is appropriate for the gestational age of the foetus [123].

Use of acetazolamide in pregnancy is controversial, and should be discussed with the individual as perinatal exposure in rodents has caused teratogenic effects [124, 125]. The postaxial limb deformities, such as polydactyly or limb deficiency, that have been reported in small animals were not found in primate studies [126]. The 
manufacturers do not recommend its use in pregnancy, but some have reported using it in other conditions and the risk of malformation was no higher than expected in the general population however few patients had exposure in the first trimester [127]. In the largest study on the use of acetazolamide in IIH, 101 pregnant women (158 pregnancies) took acetazolamide in a daily dose ranging between 250 and $2000 \mathrm{mg}$. Over half took acetazolamide prior to 13th gestational week, abortion rate (both spontaneous and induced) was higher in the acetazolamide group; the authors therefore recommended that acetazolamide should be used with caution and justification in the pregnant IIH patient [91].

Topiramate should not be used in pregnancy, due to the clear higher rate of foetal abnormalities following its use [128]. Many other headache treatments are not recommended in pregnancy; therefore the risk-benefit should be discussed with the patient.

Few patients present with IIH in pregnancy, and if there is imminent risk to the vision, serial LPs, optic nerve sheath fenestration or CSF diversion can be considered $[120,129]$. Clear communication with the obstetric and gynaecological services is key to help reassure healthcare professionals and the patient. Increased observations during pregnancy also serves to reassure. Alterations to birth plans should not be made on the basis of the historical diagnosis of IIH and only if there is likely to be precipitous visual decline in the settling of moderate to severe papilloedema. If there is a potential for a prolonged second stage of labour assisted deliveries (such as caesarean section or instrumental deliveries) should be considered.

\section{Idiopathic intracranial hypertension without Papilloedema (IIHWOP)}

This is a rare form of IIH where there is no evidence of papilloedema in the setting of raised ICP. Headache is the principle morbidity in these patients.

The diagnostic criteria for definite IIHWOP are the same as for IIH, except there is no papilloedema, but unilateral or bilateral sixth nerve palsies may be present. A diagnosis of possible IIHWOP can be made without the presence of unilateral or bilateral sixth nerve palsies, however in this case at least 3 out of the following 4 features on brain imaging need to be present: an empty sella, flattening of the eye globe, widening of the space around the optic nerve and/or transverse venous sinus stenosis [2]. In patients with IIHWOP risk of vision loss has not been identified and does not seem to develop over the disease course. The commonest symptoms of IIHWOP include headache, pulsatile tinnitus, visual phenomena such as visual obscurations, blurred vision, photopsia and diplopia (due to sixth nerve palsy) [27].

Once a diagnosis of IIHWOP is established, all patients should be counselled about weight management. As there is no threat to vision, long term visual monitoring is not required. Management of headache should be the same as in IIH. Escalation of management to surgery to control elevated ICP in IIHWOP should not be routinely considered.

\section{Conclusion}

$\mathrm{IIH}$ is a challenging disease which crosses many specialties. At investigation it requires careful exclusion of secondary causes through history, neuroimaging, LP and ophthalmic examination. Once a diagnosis is established of typical IIH, it requires regular visual monitoring, neurological input for active headache management, and direct conselling regarding weight loss. When there is no immediate threat to vision, medical treatment with acetazolamide should be considered. Less commonly required are surgical treatments to preserve vision when fulminant IIH exists. There is increasing research in this area and as evidence is published this document will require timely revision.

\section{Additional file}

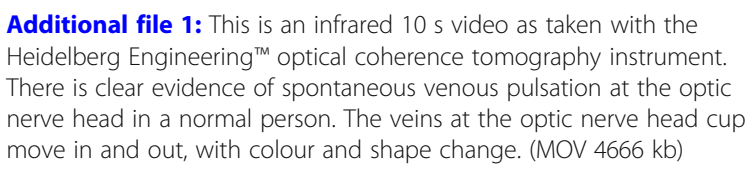

\section{Abbreviations}

11ß-HSD1: 11Beta hydroxysteroid dehydrogenase type 1; BMI: Body Mass Index; CSF: Cerebrospinal fluid; CT: Computerised tomography; GLP-1: Gut peptide glucagon-like peptide-1; ICHD: International Classification of Headache Disorders; ICP: Intracranial pressure; IHS: International Headache Society; IHH: Idiopathic intracranial hypertension; IITT: Idiopathic Intracranial Hypertension Treatment Trial; IIHWOP: Idiopathic intracranial hypertension without papilloedema; LP: Lumbar pincture; MR: Magnetic resonance; MRI: Magnetic resonance imaging; NORDIC: Neuro-Ophthalmology Research Disease Investigator Consortium; OCT: Optical coherence tomography; ONSF: Optic nerve sheath fenestration; RCT: Randomised controlled trial; RNFL: Retinal nerve fibre layer

\section{Acknowledgements}

Not applicable.

\section{Funding}

AS is funded by an NIHR Clinician Scientist Fellowship (NIHR-CS-011-028) and by the Medical Research Council, UK (MR/K015184/1).

\section{Availability of data and materials Not applicable.}

\section{Authors' contributions}

$\mathrm{JH}, \mathrm{SPM}$ and AS performed the literature review and interpretation, conceptualized and designed the statement and drafted and reviewed the manuscript. $\mathrm{RHJ}$ conceptualized, designed and drafted the manuscript. $\mathrm{KP}$ and $\mathrm{CL}$ performed a critical review of the manuscript. KP, CL and RHJ are or were Members of Council of the European Headache Federation. All authors read and approved the final manuscript

Ethics approval and consent to partcipate Not applicable.

Consent for publication Not applicable. 


\section{Competing interests}

$\mathrm{JH}$ received honoraria for consulting for and/or serving on advisory boards for Allergan, Autonomic Technologies Inc. (ATI), Chordate Medical AB, Eli Lilly, Hormosan Pharma, Novartis and Teva. He received honoraria for speaking from Allergan, Autonomic Technologies Inc. (ATI), Chordate Medical AB, Novartis and Teva. These activities are/were unrelated to the submitted work. SPM reports no conflict of interest. KP reports no conflict of interest. CL reports no conflict of interest. RHJ has received honoraria for lectures and patient leaflets from MSD, Berlin-Chemie, Menarini, Autonomic Technologies Inc. (ATI) and Pfizer; participated in medical advisory boards for ATI and Electrocore and conducted clinical trials for ATI and Eli Lilly. AJS reports no conflict of interest.

\section{Publisher's Note}

Springer Nature remains neutral with regard to jurisdictional claims in published maps and institutional affiliations.

\section{Author details}

'Basic and Clinical Neuroscience, Institute of Psychiatry, Psychology and Neuroscience, Wellcome Foundation Building, Denmark Hill Campus, King's College London, London SE5 9PJ, UK. 'Birmingham Neuro-Ophthalmology, University Hospitals Birmingham NHS Foundation Trust, Queen Elizabeth Hospital, Birmingham, UK. ${ }^{3}$ Department of Neurology, Ghent University Hospital, Ghent, Belgium. ${ }^{4}$ Headache Medical Centre, Seilerstaette Linz, Ordensklinikum Linz, Barmherzige Schwestern, Linz, Austria. ${ }^{5}$ Danish Headache Center, Department of Neurology, Rigshospitalet-Glostrup, University of Copenhagen, Glostrup, Denmark. ' ${ }^{6}$ etabolic Neurology, Institute of Metabolism and Systems Research, University of Birmingham, Edgbaston, UK.

Received: 31 July 2018 Accepted: 14 September 2018 Published online: 08 October 2018

\section{References}

1. Mollan SP et al (2016) Evolving evidence in adult idiopathic intracranial hypertension: pathophysiology and management. J Neurol Neurosurg Psychiatry 87(9):982-992

2. Friedman DI, Liu GT, Digre KB (2013) Revised diagnostic criteria for the pseudotumor cerebri syndrome in adults and children. Neurology 81(13): 1159-1165

3. Headache Classification Committee of the International Headache Society (2018) The international classification of headache disorders, 3rd edition. Cephalalgia 38(1):1-211

4. Markey KA et al (2016) Understanding idiopathic intracranial hypertension: mechanisms, management, and future directions. The Lancet Neurology 15(1):78-91

5. Hoffmann J, Goadsby PJ (2013) Update on intracranial hypertension and hypotension. Curr Opin Neurol 26(3):240-247

6. Almarzouqi SJ, Morgan ML, Lee AG (2015) Idiopathic intracranial hypertension in the Middle East: a growing concern. Saudi J Ophthalmol 29(1):26-31

7. Wall $\mathrm{M}$ et al (2014) The idiopathic intracranial hypertension treatment trial: clinical profile at baseline. JAMA Neurol 71(6):693-701

8. Giuseffi $V$ et al (1991) Symptoms and disease associations in idiopathic intracranial hypertension (pseudotumor cerebri): a case control study. Neurology 41(2 Part 1):239

9. Mulla $Y$ et al (2015) Headache determines quality of life in idiopathic intracranial hypertension. The Journal of Headache and Pain 16(1):45

10. Yri HM et al (2014) The course of headache in idiopathic intracranial hypertension: a 12-month prospective follow-up study. Eur J Neurol 21(12): 1458-1464

11. Friedman DI et al (2017) Headache in idiopathic intracranial hypertension: findings from the idiopathic intracranial hypertension treatment trial. Headache: The Journal of Head and Face Pain 57(8):1195-1205

12. Hoffmann J et al (2014) Volumetric assessment of optic nerve sheath and Hypophysis in idiopathic intracranial hypertension. AJNR Am J Neuroradiol 35(3):513-518

13. Yri $\mathrm{H}$ et al (2012) Idiopathic intracranial hypertension is not benign: a longterm outcome study. J Neurol 259(5):886-894

14. Wall M (1990) The headache profile of idiopathic intracranial hypertension. Cephalalgia 10(6):331-335
15. Bono F et al (2006) Bilateral transverse sinus stenosis predicts IIH without papilledema in patients with migraine. Neurology 67(3):419-423

16. Bono F et al (2008) Bilateral transverse sinus stenosis and idiopathic intracranial hypertension without papilledema in chronic tension-type headache. J Neurol 255(6):807-812

17. Ducros A, Biousse V (2015) Headache arising from idiopathic changes in CSF pressure. The Lancet Neurology 14(6):655-668

18. Yri HM, Jensen RH (2015) Idiopathic intracranial hypertension: clinical nosography and field-testing of the ICHD diagnostic criteria. A case-control study. Cephalalgia 35(7):553-562

19. Headache Classification Subcommittee of the International Headache Society (2004) The International Classification of Headache Disorders: 2nd edition. Cephalalgia 24(Suppl 1):9-160

20. Wall M, White WN 2nd (1998) Asymmetric papilledema in idiopathic intracranial hypertension: prospective interocular comparison of sensory visual function. Invest Ophthalmol Vis Sci 39(1):134-142

21. Bidot $\mathbf{S}$ et al (2015) Asymmetric papilledema in idiopathic intracranial hypertension. J Neuroophthalmol 35(1):31-36

22. Keltner JL et al (2014) Baseline visual field findings in the idiopathic intracranial hypertension treatment trial (IIHTT). Invest Ophthalmol Vis Sci 55(5):3200-3207

23. Lepore FE (1992) Unilateral and highly asymmetric papilledema in pseudotumor cerebri. Neurology 42(3 Pt 1):676-678

24. Maxner CE, Freedman MI, Corbett JJ (1987) Asymmetric papilledema and visual loss in pseudotumour cerebri. Can J Neurol Sci 14(4):593-596

25. Wall M (2010) Idiopathic intracranial hypertension. Neurol Clin 28(3):593-617

26. Fisayo A et al (2016) Overdiagnosis of idiopathic intracranial hypertension. Neurology 86(4):341-350

27. Digre KB et al (2009) A comparison of idiopathic intracranial hypertension with and without papilledema. Headache 49(2):185-193

28. Wall M et al (2015) Risk factors for poor visual outcome in patients with idiopathic intracranial hypertension. Neurology 85(9):799-805

29. Pollak $L$ et al (2013) Reevaluation of presentation and course of idiopathic intracranial hypertension - a large cohort comprehensive study. Acta Neurol Scand 127(6):406-412

30. Kutzko KE, Brito CF, Wall M (2000) Effect of instructions on conventional automated Perimetry. Invest Ophthalmol Vis Sci 41(7):2006-2013

31. Cello KE et al (2016) Factors affecting visual field outcomes in the idiopathic intracranial hypertension treatment trial. J Neuroophthalmol 36(1):6-12

32. Fard MA et al (2014) Quantification of peripapillary total retinal volume in pseudopapilledema and mild papilledema using spectral-domain optical coherence tomography. Am J Ophthalmol 158(1):136-143

33. Kulkarni KM et al (2014) Differentiating mild papilledema and buried optic nerve head drusen using spectral domain optical coherence tomography. Ophthalmology 121(4):959-963

34. Kaufhold F et al (2012) Optic nerve head quantification in idiopathic intracranial hypertension by spectral domain OCT. PLoS One 7(5):e36965

35. Skau M et al (2013) Diagnostic value of optical coherence tomography for intracranial pressure in idiopathic intracranial hypertension. Graefes Arch Clin Exp Ophthalmol 251(2):567-574

36. Aojula A et al (2018) Segmentation error in spectral domain optical coherence tomography measures of the retinal nerve fibre layer thickness in idiopathic intracranial hypertension. BMC Ophthalmol 17(1):257

37. Rebolleda G, Muñoz-Negrete FJ (2009) Follow-up of mild papilledema in idiopathic intracranial hypertension with optical coherence tomography. Invest Ophthalmol Vis Sci 50(11):5197-5200

38. Schmidt C et al (2012) Structural olfactory nerve changes in patients suffering from idiopathic intracranial hypertension. PLoS One 7(4):e35221

39. Khoo KF, Kunte H (2014) Olfactory dysfunction in patients with idiopathic intracranial hypertension. Neurology 82(2):189

40. Kunte $\mathrm{H}$ et al (2013) Olfactory dysfunction in patients with idiopathic intracranial hypertension. Neurology 81(4):379-382

41. Wall M, George D (1991) Idiopathic intracranial hypertension. A prospective study of 50 patients. Brain 114(Pt 1A):155-180

42. Mollan SP et al (2014) A practical approach to, diagnosis, assessment and management of idiopathic intracranial hypertension. Pract Neurol 14(6):380-390

43. Mollan SP et al (2018) Idiopathic intracranial hypertension: consensus guidelines on management. J Neurol Neurosurg Psychiat 89(10):1088-1100

44. Kaplan CP, Miner ME, McGregor JM (1997) Pseudotumour cerebri: risk for cognitive impairment? Brain Inj 11(4):293-303 
45. Sorensen PS, Thomsen AM, Gjerris F (1986) Persistent disturbances of cognitive functions in patients with pseudotumor cerebri. Acta Neurol Scand 73(3):264-268

46. Kharkar S et al (2011) Cognitive impairment in patients with Pseudotumor Cerebri syndrome. Behav Neurol 24(2):143-148

47. Yri HM et al (2014) Cognitive function in idiopathic intracranial hypertension: a prospective case-control study. BMJ Open 4(4):e004376

48. Degnan AJ, Levy LM (2011) Narrowing of Meckel's cave and cavernous sinus and enlargement of the optic nerve sheath in Pseudotumor Cerebri. J Comput Assist Tomogr 35(2):308-312

49. Hoffmann J et al (2013) Morphometric and volumetric MRI changes in idiopathic intracranial hypertension. Cephalalgia 33(13):1075-1084

50. Agid R et al (2006) Idiopathic intracranial hypertension: the validity of crosssectional neuroimaging signs. Neuroradiology 48(8):521-527

51. Degnan AJ, Levy LM (2011) Pseudotumor Cerebri: brief review of clinical syndrome and imaging findings. AJNR Am J Neuroradiol 32(11):1986-1993

52. Jacobson HG, Shapiro JH (1964) Pseudotumor Cerebri. Radiology 82:202-210

53. Jacobson DM et al (1990) Computed tomography ventricular size has no predictive value in diagnosing pseudotumor cerebri. Neurology 40(9):1454-1455

54. Ahmed RM et al (2011) Transverse sinus stenting for idiopathic intracranial hypertension: a review of 52 patients and of model predictions. AJNR Am J Neuroradiol 32(8):1408-1414

55. Riggeal BD et al (2013) Clinical course of idiopathic intracranial hypertension with transverse sinus stenosis. Neurology 80(3):289-295

56. Biousse V, Bruce BB, Newman NJ (2012) Update on the pathophysiology and management of idiopathic intracranial hypertension. J Neurol Neurosurg Psychiatry 83(5):488-494

57. Zouaoui A, Hidden G (1988) Cerebral venous sinuses: anatomical variants or thrombosis? Acta Anat (Basel) 133(4):318-324

58. Headache Classification Committee of the International Headache Society (2013) The international classification of headache disorders, 3rd edition (beta version). Cephalalgia 33(9):629-808

59. Avery RA et al (2010) Reference range for cerebrospinal fluid opening pressure in children. N Engl J Med 363(9):891-893

60. Torbey MT et al (2004) Utility of CSF pressure monitoring to identify idiopathic intracranial hypertension without papilledema in patients with chronic daily headache. Cephalalgia 24(6):495-502

61. Bono F et al (2010) Abnormal pressure waves in headache sufferers with bilateral transverse sinus stenosis. Cephalalgia 30(12):1419-1425

62. Toma AK et al (2010) Continuous intracranial pressure monitoring in pseudotumour cerebri: Single centre experience. Br J Neurosurg 24(5):584-588

63. Warden KF et al (2011) Short-term continuous intraparenchymal intracranial pressure monitoring in presumed idiopathic intracranial hypertension. J Neuroophthalmol 31(3):202-205

64. Whiteley W et al (2006) CSF opening pressure: reference interval and the effect of body mass index. Neurology 67(9):1690-1691

65. Mollan SP et al (2009) Idiopathic intracranial hypertension associated with Iron deficiency Anaemia: a lesson for management. Eur Neurol 62(2):105-108

66. Kalyvas AV et al (2017) Efficacy, complications and cost of surgical interventions for idiopathic intracranial hypertension: a systematic review of the literature. Acta Neurochir 159(1):33-49

67. Sinclair AJ et al (2011) Is cerebrospinal fluid shunting in idiopathic intracranial hypertension worthwhile? A 10-year review. Cephalalgia 31(16):1627-1633

68. Abubaker $\mathrm{K}$ et al (2011) Idiopathic intracranial hypertension: lumboperitoneal shunts versus ventriculoperitoneal shunts - case series and literature review. Br J Neurosurg 25(1):94-99

69. Banta JT, Farris BK (2000) Pseudotumor cerebri and optic nerve sheath decompression. Ophthalmology 107(10):1907-1912

70. Uretsky S (2009) Surgical interventions for idiopathic intracranial hypertension. Curr Opin Ophthalmol 20(6):451-455

71. Durst CR et al (2016) Prevalence of dural venous sinus stenosis and hypoplasia in a generalized population. Journal of Neurolnterventional Surgery 8(11):1173-1177

72. King JO et al (2002) Manometry combined with cervical puncture in idiopathic intracranial hypertension. Neurology 58(1):26-30

73. Teleb MS et al (2013) Idiopathic intracranial hypertension: a systematic analysis of transverse sinus stenting. Interventional Neurology 2(3):132-143

74. Liu KC et al (2017) Venous sinus stenting for reduction of intracranial pressure in IIH: a prospective pilot study. J Neurosurg 127(5):1126-1133

75. Daniels $A B$ et al (2007) Profiles of obesity, weight gain, and quality of life in idiopathic intracranial hypertension (pseudotumor cerebri). Am J Ophthalmol 143(4):635-641
76. Sinclair A et al (2010) Low energy diet and intracranial pressure in women with idiopathic intracranial hypertension: prospective cohort study. BMJ 7:341

77. Subramaniam S, Fletcher WA (2017) Obesity and weight loss in idiopathic intracranial hypertension: a narrative review. J Neuroophthalmol 37(2):197-205

78. Mann T et al (2007) Medicare's search for effective obesity treatments: diets are not the answer. Am Psychol 62(3):220-233

79. Hutter MM et al (2011) First report from the American College of Surgeons bariatric surgery center network: laparoscopic sleeve Gastrectomy has morbidity and effectiveness positioned between the band and the bypass. Ann Surg 254(3):410-422

80. Sjöström $L$ (2013) Review of the key results from the Swedish obese subjects (SOS) trial - a prospective controlled intervention study of bariatric surgery. J Intern Med 273(3):219-234

81. Picot J et al (2009) The clinical effectiveness and cost-effectiveness of bariatric (weight loss) surgery for obesity: a systematic review and economic evaluation. Health Technol Assess 13(41):214

82. Young MT et al (2015) Use and outcomes of laparoscopic sleeve Gastrectomy vs laparoscopic gastric bypass: analysis of the American College of Surgeons NSQIP. J Am Coll Surg 220(5):880-885

83. Manfield $\mathrm{JH}$ et al (2017) Bariatric surgery or non-surgical weight loss for idiopathic intracranial hypertension? A systematic review and comparison of meta-analyses. Obes Surg 27(2):513-521

84. Ottridge $\mathrm{R}$ et al (2017) Randomised controlled trial of bariatric surgery versus a community weight loss programme for the sustained treatment of idiopathic intracranial hypertension: the Idiopathic Intracranial Hypertension Weight Trial (IIH:WT) protocol. BMJ Open 7:e017426:1-8

85. Piper RJ et al (2015) Interventions for idiopathic intracranial hypertension. Cochrane Database Syst Rev (8):CD003434

86. Wall M et al (2014) Effect of acetazolamide on visual function in patients with idiopathic intracranial hypertension and mild visual loss: the idiopathic intracranial hypertension treatment trial. Jama 311(16):1641-1651

87. Ball AK et al (2011) A randomised controlled trial of treatment for idiopathic intracranial hypertension. J Neurol 258(5):874-881

88. Epstein DL, Grant W (1977) Carbonic anhydrase inhibitor side effects: serum chemical analysis. Arch Ophthalmol 95(8):1378-1382

89. ten Hove MW et al (2016) Safety and tolerability of acetazolamide in the idiopathic intracranial hypertension treatment trial. J Neuroophthalmol 36(1):13-19

90. Lee AG et al (2005) The use of acetazolamide in idiopathic intracranial hypertension during pregnancy. Am J Ophthalmol 139(5):855-859

91. Falardeau J et al (2013) The use of acetazolamide during pregnancy in intracranial hypertension patients. J Neuroophthalmol 33(1):9-12. https:// doi.org/10.1097/WNO.0b013e3182594001

92. Vogh BP, Langham MR (1981) The effect of furosemide and bumetanide on cerebrospinal fluid formation. Brain Res 221(1):171-183

93. Melby JM, Miner LC, Reed DJ (1982) Effect of acetazolamide and furosemide on the production and composition of cerebrospinal fluid from the cat choroid plexus. Can J Physiol Pharmacol 60(3):405-409

94. Reed DJ (1969) The effect of furosemide on cerebrospinal fluid flow in rabbits. Arch Int Pharmacodyn Ther 178(2):324-330

95. McCarthy KD, Reed DJ (1974) The effect of acetazolamide and furosemide on cerebrospinal fluid production and choroid plexus carbonic anhydrase activity. J Pharmacol Exp Ther 189(1):194-201

96. Schoeman JF (1994) Childhood Pseudotumor Cerebri: clinical and intracranial pressure response to acetazolamide and furosemide treatment in a case series. J Child Neurol 9(2):130-134

97. Davson H, Segal MB (1970) The effects of some inhibitors and accelerators of sodium transport on the turnover of $22 \mathrm{Na}$ in the cerebrospinal fluid and the brain. J Physiol 209(1):131-153

98. Murphy VA, Johanson CE (1989) Alteration of sodium transport by the choroid plexus with amiloride. Biochim Biophys Acta Biomembr 979(2):187-192

99. Katz SE et al (2002) Expression of somatostatin receptors 1 and 2 in human choroid plexus and arachnoid granulations: implications for idiopathic intracranial hypertension. Arch Ophthalmol 120(11):1540-1543

100. Panagopoulos GN et al (2007) Octreotide: a therapeutic option for idiopathic intracranial hypertension. Neurol Neurophysiol Neurosci:1

101. Celebisoy $\mathrm{N}$ et al (2007) Treatment of idiopathic intracranial hypertension: topiramate vs acetazolamide, an open-label study. Acta Neurol Scand 116(5):322-327

102. Wenzel RG, Schwarz K, Padiyara RS (2006) Topiramate for migraine prevention. Pharmacotherapy 26(3):375-387 
103. Diener HC et al (2007) Topiramate reduces headache days in chronic migraine: a randomized, double-blind, placebo-controlled study. Cephalalgia 27(7):814-823

104. Picard $\mathrm{F}$ et al (2000) Topiramate reduces energy and fat gains in lean ( $\mathrm{Fa} /$ ?) and obese (fa/fa) Zucker rats. Obes Res 8(9):656-663

105. Supuran CT (2008) Carbonic anhydrases: novel therapeutic applications for inhibitors and activators. Nat Rev Drug Discov 7(2):168-181

106. Scotton WJ et al (2018) Topiramate is more effective than acetazolamide at lowering intracranial pressure. Cephalalgia $0(0): 1-10$

107. Hornby C et al (2018) Metabolic concepts in idiopathic intracranial hypertension and their potential for therapeutic intervention. J Neuroophthalmol Publish Ahead of Print

108. Botfield HF et al (2017) A glucagon-like peptide-1 receptor agonist reduces intracranial pressure in a rat model of hydrocephalus. Sci Transl Med 9(404):1-11

109. Markey KA et al (2016) Idiopathic intracranial hypertension, hormones, and 11 beta-hydroxysteroid dehydrogenases. J Pain Res 9:223-232

110. Rauz $S$ et al (2003) Inhibition of 11 beta-hydroxysteroid dehydrogenase type 1 lowers intraocular pressure in patients with ocular hypertension. QJM 96(7):481-490

111. Sinclair AJ et al (2007) Corticosteroids, 11 beta-Hydroxysteroid dehydrogenase Isozymes and the rabbit choroid plexus. J Neuroendocrinol 19(8):614-620

112. Markey KA et al (2017) Assessing the efficacy and safety of an 11ßHydroxysteroid dehydrogenase type 1 inhibitor (AZD4017) in the idiopathic intracranial hypertension drug trial, IIH:DT: clinical methods and Design for a Phase II randomized controlled trial. JMIR Res Protoc 6(9):e181

113. Mollan SP et al (2018) Idiopathic intracranial hypertension: consensus guidelines on management. In: I Neurol Neurosurg psychiatry

114. Sinclair AJ et al (2010) Low energy diet and intracranial pressure in women with idiopathic intracranial hypertension: prospective cohort study. BMJ 341:c2701

115. Herd CP et al (2018) Botulinum toxins for the prevention of migraine in adults. Cochrane Database Syst Rev 6:Cd011616

116. Johnston I, Paterson A (1974) Benign intracranial hypertension. II. CSF pressure and circulation. Brain 97(2):301-312

117. Yiangou A et al (2018) Therapeutic lumbar puncture for headache in idiopathic intracranial hypertension: minimal gain, is it worth the pain? Cephalalgia $0(0): 1-9$

118. Scotton WJ et al (2018) Characterising the patient experience of diagnostic lumbar puncture in idiopathic intracranial hypertension: a cross-sectional online survey. BMJ Open 8(5):e020445

119. Hoffmann J (2018) The utility of the lumbar puncture in idiopathic intracranial hypertension. Cephalalgia 0(0):0333102418787301

120. Golan S et al (2013) Management and outcome of consecutive pregnancies complicated by idiopathic intracranial hypertension. Isr Med Assoc J 15(4):226-229

121. Bagga $R$ et al (2005) Choice of therapy and mode of delivery in idiopathic intracranial hypertension during pregnancy. Medscape Gen Med 7(4):42-42

122. Tang RA et al (2004) Medical and surgical management of idiopathic intracranial hypertension in pregnancy. Curr Neurol Neurosci Rep 5:398-409

123. Committee on Obstetric Practice, Committee Opinion (2013) Weight gain during pregnancy. Obstet Gynecol 121(1):210-212

124. Kojima N, Naya M, Makita T (1999) Effects of maternal acetazolamide treatment on body weights and incisor development of the fetal rat. J Vet Med Sci 61(2):143-147

125. Holmes LB, Kawanishi H, Munoz A (1988) Acetazolamide: maternal toxicity, pattern of malformations, and litter effect. Teratology 37(4):335-342

126. Wilson JG (1971) Use of rhesus monkeys in teratological studies. Fed Proc 30(1):104-109

127. Heinonen OP et al (1977) Birth defects and drugs in pregnancy. In: Kaufman DW (ed) Price unstated. American Journal of Medical Genetics. John Wright, Publishing Sciences Group, inc, Littleton, p 516

128. Weston $J$ et al (2016) Monotherapy treatment of epilepsy in pregnancy: congenital malformation outcomes in the child. Cochrane Database Syst Rev (11):CD010224

129. Huna-Baron R, Kupersmith MJ (2002) Idiopathic intracranial hypertension in pregnancy. J Neurol 249(8):1078-1081

Ready to submit your research? Choose BMC and benefit from:

- fast, convenient online submission

- thorough peer review by experienced researchers in your field

- rapid publication on acceptance

- support for research data, including large and complex data types

- gold Open Access which fosters wider collaboration and increased citations

- maximum visibility for your research: over $100 \mathrm{M}$ website views per year

At BMC, research is always in progress.

Learn more biomedcentral.com/submissions 